\section{Atopisches Ekzem erblasst vor der Bakterien-Spritze}

\author{
In einer randomisierten, Plazebo-kontrollierten Doppelblindstudie \\ führte eine einmalige intrakutane Injektion von Mykobakterien zu \\ einer signifikanten Besserung des atopischen Ekzems.
}

\begin{abstract}
önnte der extreme Rückgang von Infektionskrankheiten wie Tuberkulose die Ursache der Atopie-Epidemie sein? Kinderärzte der Universität Manchester prüften den Effekt einer intradermalen Gabe von abgetötetem Mycobacterium vaccae (SRL 172) bei atopischem Ekzem. Dazu spritzten sie 41 Kindern (Alter: 5-18 Jahre) mit mäßigem bis schwerem Ekzem einmalig Mykobakterien oder Pufferlösung (Plazebo). 56\% der Patienten litten zusätzlich an Asthma bronchiale und benötigten inhalative Steroide, 29\% an allergischer Rhinitis.
\end{abstract}

Einen Monat nach der Injektion hatte sich bei der Verum-Gruppe die Gesamtfläche der betroffenen Haut um $32 \%(p=0,01)$, nach drei Monaten um
$48 \%(\mathrm{p}=0,001)$ verkleinert. Im Gegensatz dazu zeigten die Kinder, die Plazebo erhalten hatten, keine signifikante Besserung. Bei keinem Kind verschwand das Ekzem komplett.

Ein Problem, das bei der Studie auftauchte, war eine lokale, spontan abklingende Entzündungsreaktion an der Injektionsstelle bei 62\% der VerumGruppe. Da die Plazebo-Lösung keine Reaktion hervorrief, könnte das Auftreten oder Ausbleiben einer Lokalreaktion als Hinweis für die Gruppenzugehörigkeit gedient haben. Allerdings korrelierte die Lokalreaktion nicht mit einer stärkeren Verbesserung des atopischen Ekzems. Die SRL-172-Gabe brachte keine signifikante Änderung des SerumIgE-Spiegels oder der Eosinophilenzahl.
Auch war keine Korrelation zwischen einer BCG-Impfung und dem Schweregrad des atopischen Ekzems, dem IgESpiegel oder der Eosinophilenzahl zu finden. In keiner der beiden Gruppen gab es im Beobachtungszeitraum eine signifikante Änderung der topischen Steroiddosis.

\section{Fazit}

Langerhans-Zellen besitzen nicht nur den klassischen Antigen-präsentierenden MHC-Rezeptor, sondern auch CD1a, der Lipid-Antigene z.B. von Mykobakterien präsentiert. Ob die Stimulation mit diesen Lipid-Antigenen zur „Down-Regulierung" der atopischen Antwort auf Proteine führt und ob die Mykobakterien-Applikation eine Langzeitwirkung hat, müssen zukünftige Studien klären.

Arkwright PD et al. Intradermal administration of a killed Mycobacterium vaccae suspension (SRL 172) is associated with improvement in atopic dermatitis in children with moderate-to-severe disease.

J Allergy Clin Immunol 2001; 107: 531-4.

\title{
Kein Urintest auf Atopie?
}

\section{In einer norwegischen Untersuchung mit 170 Kindern korrelierte U-EPX nicht mit dem Schweregrad der allergischen Entzündung.}

Eosin osinophile setzen bei der allergischen Entzündung unter anderen das eosinophile Protein X (EPX) frei, das nicht nur im Blut, sondern auch im Urin nachweisbar ist. Damit könnte der Schweregrad einer atopischen Erkrankung einfach und schmerzfrei im Morgenurin bestimmt werden. Vor allem bei Kindern und bei seriellen Untersuchungen wäre dies von Vorteil. $\mathrm{Zu}$ dem könnte der entsprechende Test bei Kleinkindern zwischen echtem allergischen Asthma und Asthma-ähnlichen Symptomen im Rahmen von Infektionskrankheiten unterscheiden.

In einer norwegischen Studie hatten Kinder mit akutem oder chronischem Asthma deutlich höhere U-EPXWerte als eine Gruppe gesunder Kinder. Auch bestanden zwischen Atopikern und Nicht-Atopikern deutliche Unterschiede. Die Variation der U-EPX-Wer-

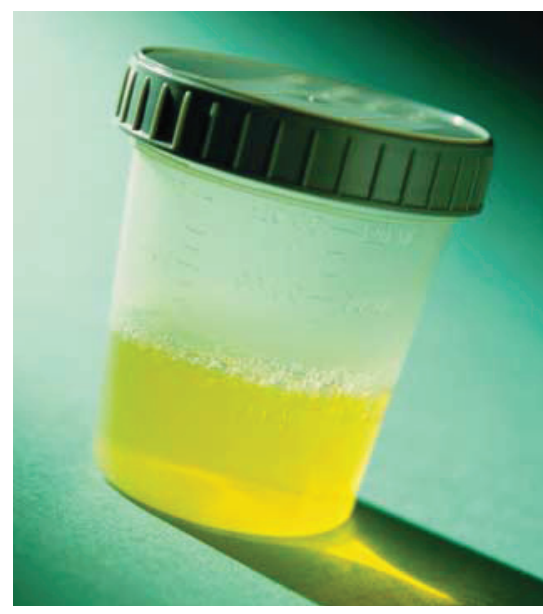

Bei Atopie ist die EPX-Ausscheidung erhöht. Die Werte streuen jedoch stark. te war jedoch so groß, dass im Einzelfall eine Unterscheidung zwischen den einzelnen Gruppen nicht möglich war. Die Werte korrelierten außerdem nicht mit dem Schweregrad der Symptome. Auch die Hoffnung, infektiös bedingte Asthma-Anfälle von frühen Manifestationen einer Atopie abzugrenzen, erfüllte sich nicht. Im Gegenteil: Bei einer Pneumonie waren die U-EPX-Werte deutlich höher als beim akuten Asthmaanfall. Der Unterschied zur Kontrollgruppe war bei Pneumonie, Laryngitis und infektiöser Rhinitis hoch signifikant.

\section{Fazit}

Was in der Theorie plausibel ist, scheitert in der Praxis häufig, und ein spezifischer Radioimmunassay für EPX dürfte in der jetzigen Form kaum die Basis für einen erwünschten Atopie-Harntest bilden.

rme

Фymar K, Bjerknes R. Urinary eosinophil protein $\mathrm{X}$ in children with asthma. Pediatr Allergy Immunol 2001; 12: 34-41. 